\title{
Association of Squamous Cell Carcinoma of lower lip with Xeroderma Pigmentosa - A Devastating disease.
}

\author{
${ }^{1}$ Dr. Kanchan Rahul Tadke, ${ }^{2}$ Dr.Vaibhav J. Lahane, ${ }^{3}$ Dr. Sanjeev V. Golhar \\ ${ }^{I}$ Associate professor Department of ENT Government Medical College and Hospital, \\ Nagpur, Maharashtra, India. \\ ${ }^{2}$ Senior Resident Department of ENT Government Medical College and Hospital, \\ Nagpur, Maharashtra, India. \\ ${ }^{3}$ Honorary Professor Indira Gandhi Government Medical college and Hospital, Nagpur, Maharashtra, India.
}

Corresponding Author -

Dr. Mrs.Kanchan R.Tadke

Flat no 704, Shivshakti apartment Tapovan Complex, Near SBI Jaiprakash Nagar branch, Nagpur, Maharashtra, India. 440025. Mobile no- 09822237810

\begin{abstract}
Xeroderma Pigmentosa is a rare inherited autosomal recessive disease characterised by inability to repair DNA damage caused by UV light. Those affected are extremely sensitive to the UV portion of the light. Affected individuals rapidly develop skin atrophy, splotchy pigmentation, telangectasias and skin cancers. These patients have increased propensity for UV radiation induced mutagenesis. Neoplasms occur commonly in the skin exposed areas. Basal cell carcinomas being the most commonly encountered variety. Squamous cell carcinoma has been infrequently reported.
\end{abstract}

Here we report a case of a 17 year old girl of Xeroderma Pigmentosa with squamous cell carcinoma of lower lip.

KEY WORDS:- Squamous cell carcinoma, Llower lip, Xeroderma Pigmentosa.

\section{Introduction}

Xeroderma pigmentosa (XP) is hetrogenous group of genetic disease resulting from inherited molecular defects in nucleotide excision repair genes. It is a rare autosomal recessive condition. The disease manifests in early childhood. These patients have a marked sensitivity to sunlight and develop serious sunburns and poikiloderma (a form of variegated hyperpigmentation and telangiectasia of the skin, followed by atrophy) in the light exposed skin (1).Xeroderma pigmentosum was first described in 1874 by Hebra and Kaposi. In 1882, Kaposi coined the term Xeroderma pigmentosum for the condition, referring to its characteristic dry,pigmented skin(2). Apart from the typical skin manifestations these patients are more prone for development of malignancies at an early age which worsens the prognosis. Basal cell carcinoma is found associated with XP in majority of the reported cases in Indian literature (3). Squamous cell carcinoma is infrequently reported. Majority of patients die before reaching adulthood because of metastasis.

\section{CASE REPORT}

A 17 years old girl presented to the ENT outpatient department with lower lip mass of two months duration .There was associated skin pigmentation all over the body since the age of two years. The pigmentation started first over the hands followed by face, legs and spreading to the rest of the body. The pigmentation was progressive and more so after exposure to sunlight. It was more prominently seen over the exposed areas of the body. There was also history of photophobia and gradual diminution of vision. There was no associated history of repeated ulcerations in the past. She had two brothers and none of her siblings or any other members of the family was affected by the disease. Her perinatal history and developmental milestones were normal.

On examination, the entire skin was covered with mixture of mottled hyper-pigmented and hypopigmented, atrophic, roundish and oval macules giving the entire skin a chequered appearance. These lesions were more numerous on the exposed area of the body, ranging in size from pin point to few mms, light to dark brown in colour. These are typically described as freckles [Fig I (a) (b)]. There was associated dryness of the skin. Ophthalmic examination revealed bilateral corneal opacities with dry eye [Fig I (c)]. Vision was diminished with finger counting at a distance of 1 meter. Local examination revealed a cauliflower like growth involving $2 / 3$ rd of the lower lip sparing the left angle of mouth and measuring $5 \times 4 \mathrm{~cm}$ in size. The growth covered with slough, crusting and haemorrhage [Fig II (a)].There was multiple cervical lymphadenopathy along 
bilateral jugular chain, none greater than $1.5 \mathrm{~cm}$ in size, mobile, firm with mild tenderness on palpation. Systemic examination including neurological functions was essentially normal.

Haemogram and serum biochemistry were within normal limits. Ultrasonography of abdomen showed mild hepatomegaly. Fine needle aspiration cytology of the cervical lymph nodes was suggestive of reactive lymphadenitis. Biopsy of the lip mass was carried out which revealed well differenciated squamous cell carcinoma with keratin pearls [FigIII $(\mathrm{a}, \mathrm{b})]$.The patient was offered wide local excision with reconstruction of the lower lip with Abbe-Estlander"s flap pedicled on the superior labial artery. Postoperative 6 months follow up showed good healing of wound with no recurrence [Fig II (b)]. Sun protective measures were explained to patient and parents.

\section{Discussion}

Xeroderma pigmentosum (XP) is an autosomal recessive genetic disorder of DNA repair characterized by cutaneous and ocular photosensitivity and an increased risk of developing cutaneous neoplasms such as basal cell carcinoma, squamous cell carcinoma and melanoma. Progressive neurological abnormalities including deafness, spasticity and cognitive impairment may develop in about $25 \%$ of XP patients. This disease involves both sexes and all races. The frequency of XP in the United States and Europe is 1 in a million (4) while in Japan it has been reported as 1 in 22000 (5). The exact incidence in India is not known. A literature search identified several case reports from India but mutation analysis had not been performed in any of the cases. Till date, 37 unrelated families with patients having XP have been reported from India. Many families have been reported from South India especially Karnataka, where significant consanguinity is observed. (6). In present study, consanguinity was not present. Handa F et al described a series of four cases and consanguinity had not been observedin those parents of the patients (7).

XP is characterised by photosensitivity, pigmentary changes, premature skin aging, neoplasia and abnormal DNA repair. The initial report of this disease was made by Hebra and Kaposi in 1874. Cleaver (1968) first reported that fibroblasts from most patients with typical XP lack the normal capacity to repair UV radiation damage to $\mathrm{DNA}(\mathbf{8})$. In $80 \%$ patients XP shows a defect in the initiation of DNA excision repair acting on pyrimidine dimers. Repair replication is reduced in all cell types examined: epidermal cells, dermal fibroblasts, lymphocytes, conjunctival cells, corneal cells, liver cells and basal carcinoma cells. Other 20\%, called XP variants have normal excision repair, but have a defect in an alternative repair process, known as post replication or daughter strand repair. 7 distinct complementation groups are recognised as A-G. The various subtypes shows clinical and epidemiological differences (9). Skin changes are noticed between 6-36 months in 75\% cases. In the case reported initial symptoms were noticed at an early age of 2 years. Freckling and increasing dryness on sun exposed surfaces are usually the earliest manifestations, varying in colour from light to dark brown and in size from pin point to a $\mathrm{cm}$ or more. They may fuse to form irregular patches of pigmentation. Superficial skin ulcers may be seen healing with difficulty and may leave disfiguring scars and contractures. The first malignant tumour may develop as early as $3^{\text {rd }} / 4^{\text {th }}$ year. In patients with XP, the mean age for skin cancer is 8 years compared to 60 years in the healthy individuals (10)

\section{Xeroderma Pigmentosa and Neoplasia}

Cultured dermal fibroblasts from XP patients have increased UV radiation induced mutagenesis. Neoplasms occur predominantly in sun exposed surfaces. UV exposure triggers a complex series of signal transduction pathways that result in immunosuppression of the skin which may well be an important factor. Basal cell carcinoma is the commonest followed by squamous cell carcinoma and malignant melanomas, Angiosarcoma and fibrosarcomas are rare. Most common site involved is face, head and neck. Squamous cell carcinoma of scalp tends to have aggressive course because of anatomical structure and vascularity. In the present case we encountered well differentiated keratinising squamous cell carcinoma of lower lip. Ocular manifestations are seen in $80 \%$ of patients. Photophobia is the commonest early symptom. This was also seen in the present case study. Other ocular complications include exposure keratitis, vascularisation, ulceration, nodular dystrophy and uveitis.

Neurologic defects are seen in $20 \%$ of patients. Microcephaly, delayed motor development, dementia, sensory-neural deafness are common disorders (11).

In a fully developed case, diagnosis is unmistakable. Mild or early cases must be differentiated from ordinary freckling. Prenatal diagnosis by amniocentesis is possible but for some families, molecular genetic techniques are now available and allow for an earlier and more reliable results (12).

For neoplasia, treatment options include early and adequate excision of all tumours. Depending on the severity of the lesion reconstruction options may range from simple closure with or without grafting or flaps. Regarding $\mathrm{XP}$ there is no specific treatment and management relies on preventing the damage where possible and dealing with the damaged and aberrant tissues at an early stage. Although definitive treatment of the disease may not be possible, the complications can definitely be prevented. UV rays upto $320 \mathrm{~nm}$ are harmful and may produce 
malignant change. Hence the patients have to be protected from sunlight. Eye protection by artificial tears and soft contact lenses is very useful. Different treatment modalities like topical 5-fluorouracil, oral retinoids, chemical peeling, dermabrasion and excision with grafting have been tried for premalignant and malignant lesions more or less successfully (13).

In terms of prognosis, the disease is often fatal before the age of 10 years and two-third affected die before 20 years of age. Multiple metastasis of squamous cell carcinoma or malignant melanoma are one of the important cause of death. However many patients die from infection, to which they are abnormally susceptible, or from neurological complications. Thus high level of clinical suspicion, early recognition and meticulous treatment are important for successful outcome of disease.

\section{Conclusion}

$\mathrm{XP}$ is a rare and devastating disease.In those affected malignancy may occur at an early age worsening the prognosis. High level of clinical suspicion, early diagnosis and prompt management may prove fruitful. Immediate implementation of rigorous sun protection measures with patient and family education may prolong the lives of persons with XP. Genetic counselling plays a very important role in prevention of the disease.

Conflict of Interest - The authors declare that there is no conflict of interest regarding the publication of this paper.'

Sponsorship Statements/Financial Disclosure Statements - no sponsorship.

Ethical approval - This article does not contain any studies with animals performed by any of the authors.

Informed consent - Informed consent was obtained from parents and patient included in the study.

\section{References}

[1]. Norgaurer J, Idrko M, Panther E, Hellstern O, Herouy Y, Xeroderma pigmentosum, Eur J Dermatol 2003, Jan-Feb;13 (1): 4-9.

[2]. Horenstein MG, Diwan AH. Xeroderma pigmentosum. emedicine (http://www.emedicine.BANGLADESH J CHILD HEALTH 2005; VOL 29 (3) : 105 Xeroderma Pigmentosum with Squamous Cell Carcinoma com/derm/topic 462.htm, accessed on 08 June 2005).

[3]. SarojiniPA,MalhotraYK,BhutaniLK,KandhariKC.The de-sanctiscacchionesyndrome.Indian J DermVener 1969;35:247.

[4]. Kleijer WJ, Laugel V, Berneburg M, Nardo T, Fawcett H, Gratchev A, et al. Incidence of DNA repair deficiency disorders in western Europe: Xeroderma pigmentosum, Cockayne syndrome and trichothiodystrophy. DNA Repair (Amst) 2008;7:744-50.

[5]. Hirai Y, Kodama Y, Moriwaki S, Noda A, Cullings HM, Macphee DG, et al. Heterozygous individuals bearing a founder mutation in the XPA DNA repair gene comprise nearly 1\% of the Japanese population. Mutat Res 2006;601:171-8

[6]. Sharma S, Deshmukh AD, Bal MM, Chaukar DA, Dcruz AK. Angiosarcoma of the scalp associated with Xeroderma pigmentosum. Indian J Med PaediatrOncol 2012;33:126-9.

[7]. Handa F, Manchanda RL, Singh R. Xeroderma Pigmentosum. Indian J DermatolVenereolLeprol 1968; 34: 231-36.

[8]. Cleaver JE. DNA damage and repair in light- sensitive human skin disease. J Invest Dermatol 1970;181-95.

[9]. Cook PR, Brazell IA, Pawsey SA et al. Changes induced by ultraviolet light in the superficial DNA of lymphocytes for subjects with Xeroderma pigmentosum and normal controls. J cell Sci, 1978; 29: 117-27.

[10]. Baisakh MR, Khalkho J, Khan MA. Multiple squamous cell carcinoma of face in a child with xeroderma pigmentosa: A case report. AustralAsian J Cancer. 2009;8:133-5.

[11]. Lambert WC,Kno HR, LambetMW.Xeroderma Pigmentosa (Review) ,1995;Vol 13:169-209.

[12]. R.H. Champion, J.L. Burton, D.A. Burns, S.M. Breathnach. Rook/Wilkemd/Ebling) textbook of Dermatology, volume $16^{\text {th }}$ edition. Pg 407-412.

[13]. HemantSaraiya, MukulTrivedi, Jayesh Patel, J.T.Jhala, Indian journal of plastic surgery, July- December 2007 Vol 40, Issue2, pg 209-212.

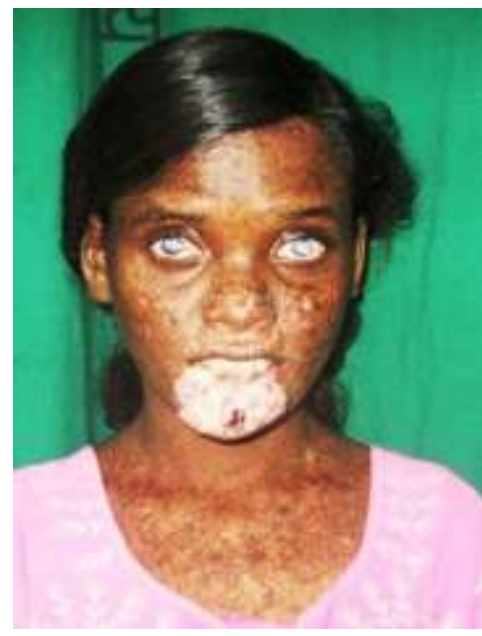

(a)

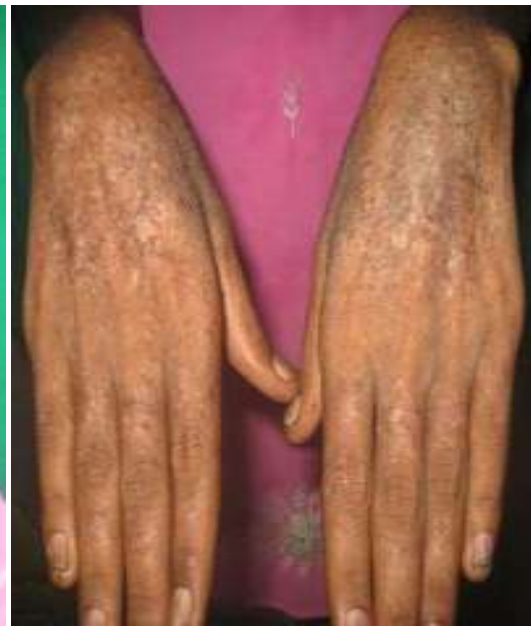

(b)

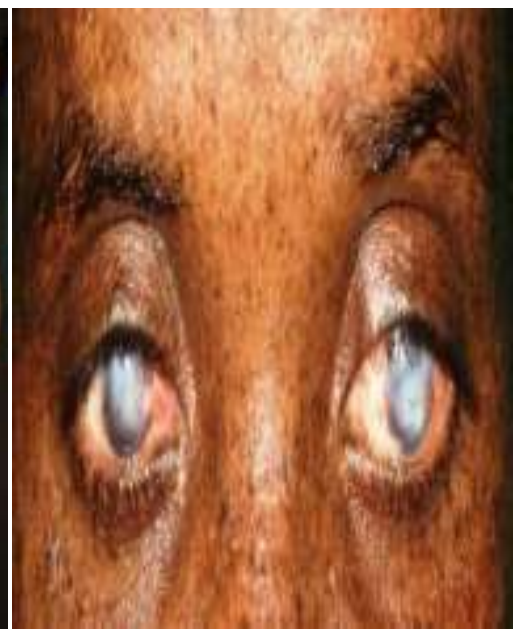

(c) 
Figure I - (a) (b) - Mottled hyper-pigmented and hypo-pigmented, atrophic, roundish and oval macules giving the entire skin a chequered appearance, ranging in size from pin point to few mms, light to dark brown in colour. These are typically described as freckles.

(c) - Bilateral corneal opacities with dry eye.

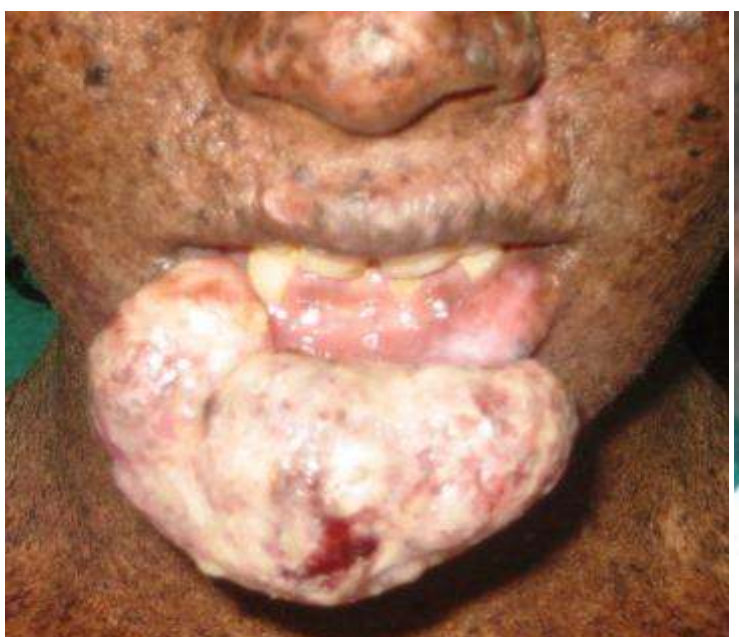

(a)

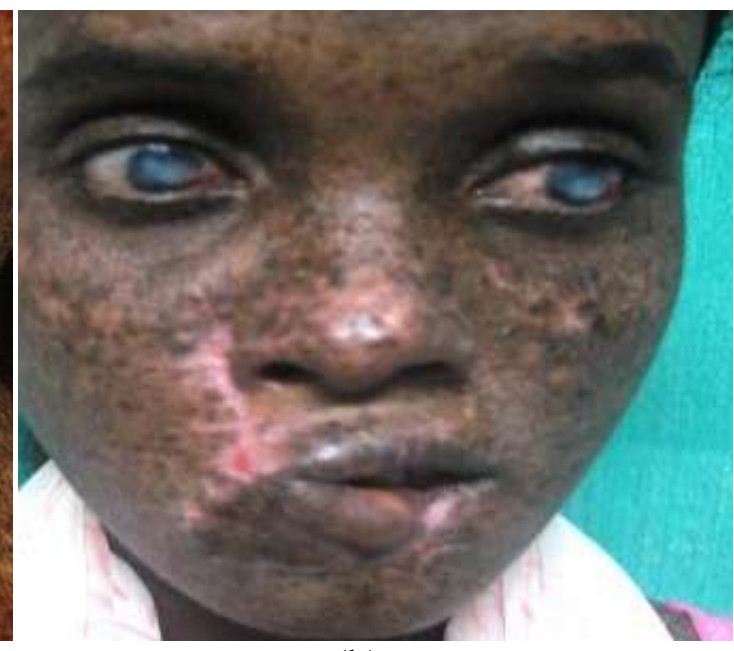

(b)

Figure II - (a) - Cauliflower like growth involving $2 / 3$ rd of the lower lip sparing the left angle of mouth and measuring $5 \times 4 \mathrm{~cm}$ in size. The growth covered with slough, crusting and haemorrhage.

(b) -Post-operative photograph following wide local excision with reconstruction of the lower lip with AbbeEstlander's flap pedicled on the superior labial artery.

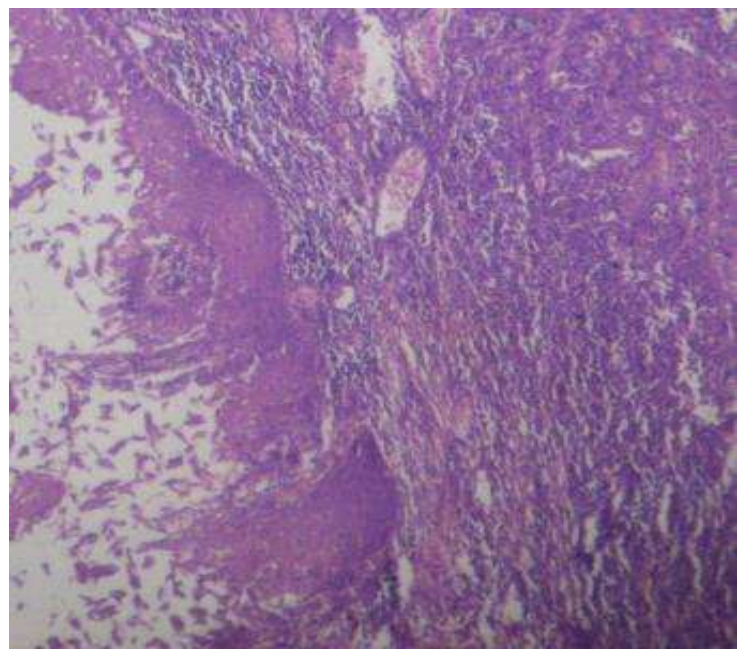

(a)

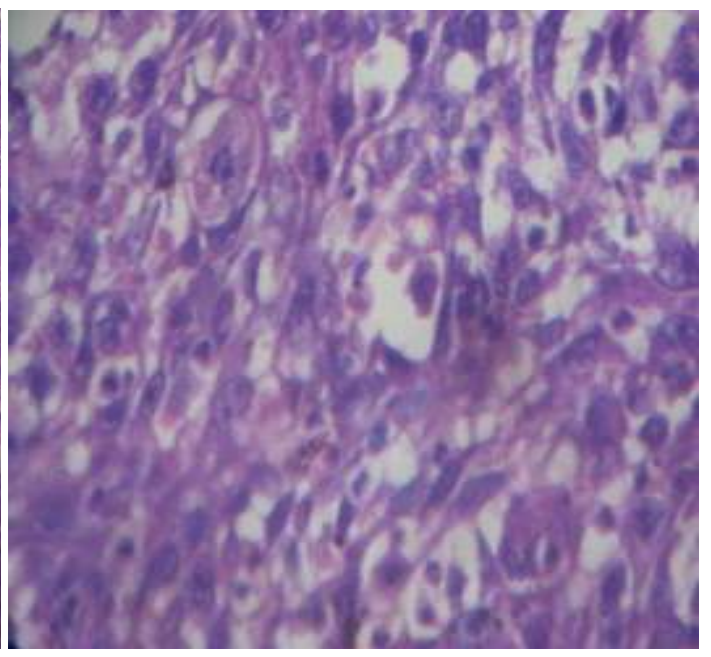

(b)

Figure III (a \&b) - Biopsy of the lip mass revealed well differentiated squamous cell carcinoma with keratin pearls 